\title{
Values and Support for Immigration: A Cross-Country Comparison
}

\author{
Eldad Davidov, Bart Meuleman, Jaak Billiet and Peter Schmidt
}

In this article, we estimate and compare the effects of two value dimensions taken from the theory of basic human values-namely, self-transcendence and conservation-on attitudes toward immigration in 19 countries. Data from the first wave (2002-03) of the European Social Survey (ESS) is utilized for the analyses. This cross-national survey measures basic human values with a new 21-item instrument. Attitudes toward immigration are operationalized using two dimensions: willingness to allow immigrants into the country and rejection of conditions to allow them. Effects of the value dimensions on immigration attitudes are compared across 19 nations using multiple-group multiple-indicators structural equation modelling (MGSEM). We hypothesize that these effects are equal across countries. The critical statistical legitimacy for comparing these effects across countries is discussed in detail, and partial measurement invariance is evidenced. The MGSEM provides strong support for our hypotheses in 17 countries: self-transcendence displays a positive effect on support for immigration, and conservation a negative effect. This result is robust also after accounting for several individual and contextual variables. Effects are found to differ a little across countries. It is shown that clusters of countries with equal effect sizes can be distinguished, and possible explanations for effect size differences are discussed.

\section{Introduction}

Unarguably, during the last decade migration flows into Europe are on the rise. According to the Organisation for Economic Cooperation and Development (OECD) statistics, the annual influx of immigrants into the EU-15 (without Greece and Austria ${ }^{1}$ ) has evolved from $1,433,000$ in 1994 , more than $1,719,000$ in 1999 , to 2,476,000 in 2004 (OECD, 2006). Electoral successes of anti-immigration parties indicate that in the same Europe, negative attitudes toward immigrants or immigration are quite widespread (for example, Anderson, 1996; Lubbers, 2001). Survey research confirms the picture that exclusionist attitudes prevail in large sections of the autochthonous populations.
The literature contains numerous studies that attempt to gain a deeper understanding of anti-immigration feelings and negative out-group attitudes. Traditionally, these studies have focused on the effects of structural variables, economic interests, perceived threat, and symbolic motives (Coenders and Scheepers, 1998; Hagendoorn and Nekuee, 1999; Fetzer, 2000; Scheepers et al., 2002; Raijman et al., 2003; Dustmann and Preston, 2004; Gijsberts et al., 2004; Raijman and Semyonov, 2004; Sniderman et al., 2004; Semyonov et al., 2006; Sides and Citrin, 2007). However, far less studies investigate the direct relation between human values and attitudes (exceptions are, e.g., Rokeach, 1973; Peterson, 1994; Sagiv and Schwartz, 1995; Altemeyer, 1998; Duriez et al., 2002; Pantoja, 2006; 
Schwartz, 2006). Several reasons can be given for the existence of this lacuna. Firstly, the value concept has never occupied the central position it might deserve in social sciences. Secondly, value research has suffered a long time from the absence of an agreed-upon scale to measure values (Hitlin and Piliavin, 2004). Nevertheless, the theoretical relevance of values to explain attitudes is paramount. After all, human values can be seen as abstract principles that underpin attitudes toward more specific objects, such as immigration (Rokeach, 1973).

In this article, an attempt is undertaken to provide an underlying mechanism of the link between human values and attitudes toward immigration. Thus, the objective of the study is neither a human value theory test, nor a study of attitudes toward immigration, ${ }^{2}$ but we rather focus on the relation between the two. This article differs from previous studies in several respects. First and foremost, this is a comparative research. The link between human values and attitudes toward immigration is tested simultaneously in 19 different European countries and the equality of the effects across nations is assessed. This allows us to evaluate the cross-cultural robustness of the findings. Consequently, the necessary attention will also be paid to the cross-cultural equivalence of the measurements (Hui and Triandis, 1985; Steenkamp and Baumgartner, 1998; Vandenberg and Lance, 2000; Harkness et al., 2003), an issue that is neglected too often. Secondly, one of the aspects of attitudes toward immigration this study focuses upon-the rejection of conditions for allowing immigrants-has not been linked to human values before.

\section{Theoretical Overview: Using Values to Explain Attitudes Toward Immigration}

\section{Attitudes versus Human Values}

In the past, the concepts value and attitude have been used interchangeably far too often. A clear delineation of both concepts is a necessary condition for grasping the connection between values and attitudes. Following Rokeach (1968: 550), an attitude can be defined as 'an enduring organization of several beliefs focused on a specific object or situation, predisposing one to respond in some preferential manner'. Ajzen (1993: 41) similarly defines an attitude as 'an individual's disposition to react with a certain degree of favorableness or unfavorableness to an object, behavior, person, institution, or event - or to any other discriminable aspect of the individual's world'. In other words, attitudes can be seen as consistent tendencies to evaluate a particular object positively or negatively. Beliefs with respect to the given object form the foundation on which the evaluation is based. Other authors phrased similar ideas in slightly different words (Fishbein and Ajzen, 1975; Eagly and Chaiken, 1993). In this contribution, we consider attitudes toward two concrete objects: (i) the openness of a country for immigration, and (ii) conditions for allowing immigrants into the country. Thus, both attitude variables in this study deal with the readiness of individuals to accept the arrival of newcomers-often with a different ethnic background-into 'their' society. These attitudes can be seen as concrete translations of ethnocentrism (Sumner, 1960), a broad concept that contains many more facets like social distance, perception of ethnic threat, and avoidance of out-group contact (LeVine and Campbell, 1972).

Human values, on the other hand, can be defined as 'desirable transsituational goals, varying in importance, that serve as guiding principles in the life of a person or other social entity' (Schwartz, 1994: 21). To avoid any conceptual confusion, we elaborate the value definition by distinguishing it from the attitude concept. In the first place, a value is a belief, namely, the belief that some end-state or mode of conduct is preferable over another end-state or mode of conduct (Rokeach, 1973). An attitude, on the contrary, is the evaluative sum of several beliefs with respect to a certain object (Fishbein and Ajzen, 1975). Secondly, values transcend specific situations, whereas attitudes explicitly refer to one specific object. Consequently, the number of distinguishable human values is limited: Rokeach (1968), for instance, mentions about six dozen values, and Schwartz (1994) discerns 10 human value types. Conversely, one can have as many attitudes as there are objects in the world (Rokeach, 1973; Fishbein and Ajzen, 1975). Thirdly, values occupy a more central position than attitudes within the personality of an individual (Hitlin and Piliavin, 2004). A minimal level of value stability is necessary for the continuity of personality and society (Rokeach, 1973). Attitudes, on the other hand, are more volatile since they refer to one specific object. There is a huge potential for attitude change because attitudes depend on numerous beliefs that could be altered in so many ways (Ball-Rokeach and Loges, 1994).

Schwartz (1992) postulated a theory that describes 10 basic types of human values that are distinguished by their motivational goals (Table 1). One of the most appealing features of Schwartz' theory is the integration of basic value types into a broader value system. 
Table 1 Shalom Schwartz' 10 basic human value types and their motivational emphases

\section{Value type Motivational emphasis}

\begin{tabular}{|c|c|}
\hline Power & $\begin{array}{l}\text { Social status and prestige, control or } \\
\text { dominance over people and resources }\end{array}$ \\
\hline Achievement & $\begin{array}{l}\text { Personal success through demonstrating } \\
\text { competence according to social } \\
\text { standards }\end{array}$ \\
\hline Hedonism & $\begin{array}{l}\text { Pleasure and sensuous gratification for } \\
\text { oneself }\end{array}$ \\
\hline Stimulation & $\begin{array}{l}\text { Excitement, novelty, and challenge in } \\
\text { life }\end{array}$ \\
\hline Self-direction & $\begin{array}{l}\text { Independent thought and action - } \\
\text { choosing, creating, and exploring }\end{array}$ \\
\hline Universalism & $\begin{array}{l}\text { Understanding, appreciation, tolerance, } \\
\text { and protection for the welfare of all } \\
\text { people and for nature }\end{array}$ \\
\hline Benevolence & $\begin{array}{l}\text { Preservation and enhancement of the } \\
\text { welfare of people with whom one has } \\
\text { frequent personal contact }\end{array}$ \\
\hline Tradition & $\begin{array}{l}\text { Respect, commitment, and acceptance } \\
\text { of the customs and ideas that traditional } \\
\text { culture or religion provide }\end{array}$ \\
\hline Conformity & $\begin{array}{l}\text { Restraint of actions, inclinations, and } \\
\text { impulses likely to upset or harm others } \\
\text { and violate social expectations or norms }\end{array}$ \\
\hline Security & $\begin{array}{l}\text { Safety, harmony, and stability of society, } \\
\text { or relationships, and of self }\end{array}$ \\
\hline
\end{tabular}

Adopted from Sagiv \& Schwartz (1995: 438).

The dynamic relations between the motivational types are represented by a classification of the 10 value types into a circular continuum (Figure 1). Adjacent value types share some motivational emphases and are compatible, therefore, while values that are further away are often more conflicting or even diametrically opposed. Universalism and benevolence, for example, share transcendence of selfish interests, while the opposite value type 'achievement' focuses on personal success (Schwartz, 1994). The circular structure also makes it possible to distinguish four higher order value types that can be ordered along two orthogonal dimensions: openness to change versus conservatism and selfenhancement versus self-transcendence (Schwartz, 1992).

Recently, Schwartz et al. developed the Portrait Values Questionnaire (PVQ). This measurement instrument for human values can be applied in large population surveys since it does not demand a high level of abstract thinking. The PVQ was validated in many cultures (Schwartz et al., 2001). In the vast majority of the samples, the hypothesized circular structure was found. This supports the claim that at

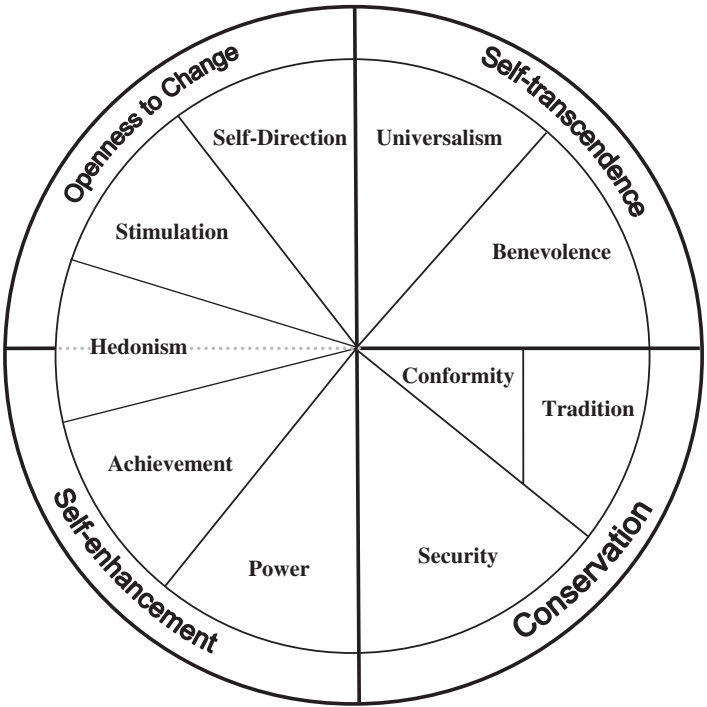

Figure 1 Structural relations among the 10 values and the two dimensions

least some aspects of the content and structure of human values are universal (Schwartz, 1994).

\section{The Relation between Human Values and Attitudes Toward Immigration: Looking at the Underlying Mechanism}

The conceptual differences between values and attitudes sketched above reveal important information about their relationship. Commonly, it is assumed that human values are general standards that underpin concrete attitudes and behaviour. Values can be seen as abstract principles that guide concrete attitudes toward particular objects (Rokeach, 1968). Several conceptions of how the value-attitude linking process operates are possible. Firstly, values can be seen as determining the weight that is given to different beliefs when an overall evaluation of an attitude object is made (Esses et al., 1993). Alternatively, Sagiv and Schwartz (1995) argue that values will influence the attitude toward a certain object if this object has relevant consequences for the attainment of the motivational goals that are associated with these respective values. In this sense, human values whose motivational goals are promoted or blocked by the arrival of immigrants will affect attitudes toward immigration.

Concrete hypotheses can be derived from relating immigration to the attainment of specific motivational goals. Immigration can be seen as an obstacle for values of the higher order type conservation, since 
immigration often brings along changing traditions and norms. We can expect that exclusionist attitudes are more widespread among individuals who list commitment to customs and traditions (tradition) high among their priorities. Analogously, persons who give much importance to honouring social expectations and norms (conformity) or social order and stability (security), will be probably less willing to accept immigrants (Sagiv and Schwartz, 1995). These hypotheses should come as no surprise since the value types tradition, conservation, and security are closely related to authoritarianism. In their classical study, Adorno et al. found a positive relation between ethnocentrism and an authoritarian personality. Among others, fundamental characteristics of this personality type are the tendency to obey social conventions and traditions (conventionalism) and an aggressive attitude toward violators of these traditions (authoritarian aggression) (Adorno et al., 1950).

Values that pertain to the self-transcendence higher order type are expected to be connected to positive attitudes toward immigration. This should be especially the case for universalism since this value type comprises tolerance, understanding, and showing concern for the welfare of all human beings. Admitting immigrants into the country offers possibilities to realize these motivational goals. The relationship between benevolence and attitudes toward immigration will probably be positive as well, albeit weaker. After all, benevolence refers, in the first place, to the enhancement of the welfare of personal contacts rather than all human beings (Schwartz, 1994).

There is far less consensus on the expected relationships between attitudes toward immigration and the other two higher order value types. Schwartz (1994) and Sagiv and Schwartz (1995) expect values of the openness to change higher order type (self-direction and stimulation) to correlate positively with proimmigration attitudes. In this line of thinking, immigration yields opportunities to explore new and different ways of life-motivational goals that are central to the self-direction and stimulation value types. On the other hand, Duriez et al. (2002) stress that the presence of outgroups may also be perceived as threatening for one's pursuit of novelty. There also exists some debate on the relation between self-enhancement value types (achievement and power) and such attitudes. Realistic group conflict theory (Blalock, 1967; Sherif and Sherif, 1969; Olzak and Nagel, 1986) starts from the proposition that negative out-group attitudes originate from economic and political competition. Persons that consider personal success (self-achievement) or wealth and social power (power) of paramount importance are likely to perceive immigrants as greater rivals. Therefore, an association between these two value types and negative attitudes toward immigration is expected (Duriez et al., 2002). Yet, Sagiv and Schwartz (1995) underline a second process that operates in the opposite direction. For the dominant group, the presence of out-groups might also provide opportunities to gain wealth, power, and control. Because immigration can be perceived both as a threat and as an opportunity, Sagiv and Schwartz conclude that a correlation near zero is to be expected.

Thus, according to theory, only the values of the conservation and self-transcendence type have unambiguous effects on attitudes toward immigration. Effects of the values pertaining to the self-enhancement and the openness to change higher order types have far less robust theoretical foundations and are expected to be ambiguous. For this reason, this study will exclusively focus on the hypotheses concerning the self-transcendence and conservation value types. In the past, empirical studies-principally American-have provided empirical support for these hypothesized effects. Rokeach (1973) found that white Americans with pro-Black attitudes give higher priority to values that pertain to Schwartz universalism or benevolence type, and a lower priority to values of security, conformity, or tradition value types. Although sometimes a different terminology is used, other studies confirm these results for the American (Katz and Hass, 1988; Pantoja 2006), Israeli (Sagiv and Schwartz, 1995), Flemish (Duriez et al., 2002), and German (Iser and Schmidt, 2005) contexts.

Summarizing, we expect individuals scoring high on self-transcendent values to maintain stronger positive attitudes toward immigration. In contrast, individuals scoring high on conservation values are expected to have more negative attitudes. We start from the hypothesis that these relationships between values and attitudes will be invariant across countries. We find no indices in the literature for possible betweencountry differences in the value-attitudes relation. Schwartz $(1992,1994)$ evidences on the contrary a high degree of universality of the four higher order value types and of their organization into two dimensions. Besides that, previous research has given ample support for the relation between authoritarianism, anomia, and ethnic pre-judice. This is one of the strongest and most stable relations that are documented in empirical studies in a large number of countries (see for example Roberts and Rokeach, 1956; Billiet et al., 1996; Meloen et al., 1996). Ethnic pre-judice is conceptually (and empirically) closely related to the attitudes toward immigration that are studied here. Conservation values are built on several items that are 
Table 2 Wording of the items of the ESS Human Values Scale

Dimension Value Item \# (according to its order in the ESS questionnaire)
and Wording (Male Version)

Self-transcendence Universalism 3. He thinks it is important that every person in the world be treated equally. He believes everyone should have equal opportunities in life. 8. It is important to him to listen to people who are different from him. Even when he disagrees with them, he still wants to understand them. 19. He strongly believes that people should care for nature. Looking after the environment is important to him.

Benevolence 12. It's very important to him to help the people around him. He wants to care for their well-being.

18. It is important to him to be loyal to his friends. He wants to devote himself to people close to him.

Conservation Tradition 9. It is important to him to be humble and modest. He tries not to draw attention to himself.

20. Tradition is important to him. He tries to follow the customs handed down by his religion or his family.

Conformity 7. He believes that people should do what they're told. He thinks people should follow rules at all times, even when no-one is watching.

16. It is important to him always to behave properly. He wants to avoid doing anything people would say is wrong.

Security 5. It is important to him to live in secure surroundings. He avoids anything that might endanger his safety.

14. It is important to him that the government insures his safety against all threats. He wants the state to be strong so it can defend its citizens.

conceptually very close to authoritarianism. Selftranscendence values are to some extent the opposite of anomia. Therefore, we expect that the relationship between the attitudes toward immigration and the values is also stable and invariant over all countries.

\section{Data and Indicators}

To test the cross-cultural robustness of the link between values and attitudes, the first wave of the European Social Survey (ESS) is used. For each of the 19 European countries, ${ }^{3}$ respondents were selected by means of strict probability samples of the resident populations aged 15 years and older. The countries and their respective numbers of respondents that completed the basic human values scale and the attitude items on immigration are: Austria (AT) $(2,257)$, Belgium (BE) $(1,899)$, Czech Republic (CZ) $(1,360)$, Denmark (DK) (1,506), Finland (FI) $(2,000)$, France (FR) (1,503), Germany (DE) (2,919), Great Britain (GB) (2,052), Greece (GR) (2,566), Hungary (HU) (1,685), Ireland (IE) $(2,046)$, Netherlands (NL) $(2,364)$, Norway (NO) (2,036), Poland (PL) $(2,110)$, Portugal (PT) $(1,510)$, Slovenia (SI) $(1,519)$, Spain (ES) $(1,729)$, Sweden (SE) $(1,999)$, and Switzerland (CH) $(2,037)$. Thus, the total number of respondents from the 19 countries is 37,097 . The data were taken from website http://ess.nsd.uib.no. Translation of the questionnaire into each native language followed the rigorous procedures for cross-cultural surveys set out in Harkness et al. (2003, chapter 3).

The ESS human value scale is derived from the earlier 40-item PVQ (Schwartz et al., 2001). However, space and budget limitations required reducing the number of items in the ESS 2003. Some items were dropped, others changed so as to include the spectrum of different aspects of each value. The 21 value items in the ESS are verbal portraits of 21 different people, gender matched with the respondent. Each portrait describes a person's goals, aspirations, or wishes that point implicitly to the importance of a value. For each portrait, the respondents were asked to tell how strong the similarities are between themselves and the described person, using 6-point Likert scales (1-'very much like me' to 6-'not like me at all'). From these scores, the respondents' values were inferred. In this study, the variables were recoded so that a higher score indicates stronger similarity. Table 2 presents the wording of the items that were included in the analysis. These items measure the values belonging to the dimensions self-transcendence and conservation, namely, universalism, benevolence, tradition, 
Table 3 Wording for the items measuring attitudes toward immigration

Attitude

Item \# (according to its order in the ESS questionnaire) and Wording
Allow
D5. To what extent do you think [country] should allow people of a different race or ethnic group from most [country] people to come and live here?

D7. To what extent do you think [country] should allow people from the poorer countries in Europe to come and live here?

D8. To what extent do you think [country] should allow people from the richer countries outside Europe to come and live here?

D9. To what extent do you think [country] should allow people from the poorer countries outside Europe to come and live here?

Please tell me how important you think each of these things should be in deciding whether someone born, brought up and living outside [country] should be able to come and live here. D10. How important should it be for them to have good educational qualifications?

D16. How important should it be for them to have work skills that [country] needs? conformity, and security. Two portraits were utilized to operationalize each value. Only universalism was operationalized by three items due to its broad content.

Two aspects of attitudes toward immigration are considered in this study. The first attitude variable refers to the willingness to let immigrants into the country ('allow'). Each of the items of this measurement scale inquires whether respondents prefer their country to allow many or few immigrants of a certain group. To register the answers of the respondents 4-point scales (1-allow none, 4-allow many) are used. The second attitude variable, which we named 'no conditions', refers to the importance placed on certain conditions for allowing immigrants into the country. For example, respondents were asked whether they consider good educational qualifications a necessary condition for allowing immigration. The two items that indicate support for conditions are measured on an 11-point scale (0-extremely unimportant, 10 - extremely important) ${ }^{4}$ Both attitude variables are recoded in this study in such a manner that a higher score reflects a more open attitude toward immigration, i.e. a greater willingness to allow immigrants and less importance placed on conditions for immigration. These two sets of items were selected based on prior confirmatory factor analyses that we conducted and represent the two different dimensions of attitudes toward immigration. Table 3 presents the question wording for each of the items, grouped by attitude variable.

\section{Data Analysis}

Instead of working with single value types, we measure the two higher order dimensions self-transcendence and conservation directly by the items. Self-transcendence represents two values: universalism, measured by three indicators, and benevolence, measured by two. These five indicators are used to measure self-transcendence directly. Similarly, conservation reflects three other values: tradition, conformity, and security, each measured by two indicators. We utilize the six indicators to measure conservation directly. From a purely theoretical point of view, it would be interesting to use the single values as explanatory variables. After all, some of the single values that are combined into the higher order dimensions are expected to have a different effect on attitudes toward immigration. We hypothesize, for example, that universalism will have a stronger positive effect than benevolence. However, the ESS human value scale does not result in clear-cut measurements of the single values. Instead, all indicators load very strongly on the higher order dimensions. Models where single values are used tend to suffer from multicollinearity. The problem arises especially when using the highly correlated specific values as predictors.

There is also a strong theoretical justification for using higher order dimensions. Davidov et al. (in press) argue that the division of the domain of value items into 10 distinct values is an arbitrary convenience. The circular arrangement of values represents a continuum of related motivations, much like the circular continuum of colours, rather than a set of discrete motivations. One could reasonably partition the domain of value items into broader or more finetuned distinct value constructs, depending on how finely one wishes to discriminate among motivations.

\section{Testing for Invariance}

Before the effects of values on attitudes toward immigration can be compared cross-culturally, we have to guarantee that the measurements possess the characteristic of measurement invariance. This notion 
refers to the question 'whether or not, under different conditions of observing and studying phenomena, measurement operations yield measures of the same attribute' (Horn and McArdle, 1992: 117). If invariance is absent, interpretations of between-group comparisons become highly problematic (Vandenberg and Lance, 2000). Various hierarchical levels of invariance can be distinguished, each with its own consequences for the comparability of scores across groups (Steenkamp and Baumgartner, 1998). In this study, we want to make cross-national comparisons of effect parameters (regression coefficients). For this type of comparison to be allowed, at least the metric invariance or equivalence of the factor loadings between items and theoretical constructs we are exploring is needed (Rock et al., 1978; Hui and Triandis, 1985; Steenkamp and Baumgartner, 1998; Cheung and Rensvold, 2002; Harkness et al., 2003; for an application of an invariance test on the human values scale from the ESS, see Davidov et al., in press; for an application of an invariance test on the attitude variables from the ESS, see Meuleman and Billiet, 2005).

There are various techniques to test for measurement invariance, one of which is multiple-group confirmatory factor analysis (MGCFA; Jöreskog, 1971). To assess metric equivalence, we test whether the factor loading of each item on its corresponding construct is the same across all nations. Only if this measurement invariance is supported, can we proceed with the cross-country comparison of the effects of values on attitudes toward immigration. However, for cross-cultural comparisons to be allowed, it is not necessary that all factor loadings are invariant (full measurement invariance). Various scholars have argued the comparability of the meaning of constructs is guaranteed when at least two indicators per construct are equal across all countries (Byrne et al., 1989; Steenkamp and Baumgartner, 1998). Thus, if full measurement invariance appears not to hold, we can still resort to this partial measurement invariance.

To test for metric invariance, we estimate a multigroup model for the 19 countries. ${ }^{5}$ This model contains four latent variables: two higher order values and two immigration attitudes. A 'top-down' strategy is applied: we start with the most restrictive model, a fully invariant model where all loadings are constrained to be equal across all countries (model 1-full measurement equivalence). Next, we test if freeing some of the constrained factor loadings leads to a substantially improved model fit or to substantial parameter changes (Saris et al., 1987; Kaplan, 1989).

The overall fit measures $(\mathrm{CFI}=0.95, \mathrm{NFI}=0.94$, RMSEA $=0.01$, Pclose $=1.0$ ) suggest that model 1 is acceptable. However, modification indices pointed to misspecifications in the model. Therefore, in model 2 we conducted several modifications. In 12 countries we changed the constraints on one or more item loadings sequentially. In some countries, we added crossloadings between indicators supposed to measure one value dimension to the other value dimension. However, these cross-loadings were low and not substantial. In other cases, we had to relax the measurement invariance constraints for some items. As a result, model 2 displays only partial measurement invariance for some of the countries. No modifications were needed for the attitude variables (a table summarizing the modifications may be obtained from the authors).

Model 2 did not produce any substantial improvement in the fit measures compared with the more restrictive model $1 \quad(\mathrm{CFI}=0.95, \quad \mathrm{NFI}=0.94$, RMSEA $=0.01$, Pclose $=1.0$ ). After these adaptations, the program neither proposed further substantial model modifications nor expected large parameter changes. In this final model, all factor loadings were statistically significant and most standardized factor loadings were over 0.4 (a table summarizing the standardized and unstandardized factor loadings may be obtained from the authors). Together with the good fit indices, this indicates that the items provide an acceptable measurement of the latent constructs in the model. Furthermore, with the partial metric invariance established, we may now use model 2 to compare the relationships among values and attitudes toward immigration across countries.

\section{Effects of Values on Attitudes Toward Immigration}

Before starting with the empirical analyses, let us summarize the main hypotheses from the theory section. We expect self-transcendence to have a significant positive effect on the willingness to allow immigrants into the country (the variable 'allow') (Hypothesis 1) and on the rejection of conditions to allow immigrants into the country (the variable 'no conditions') in all countries (Hypothesis 2). In contrast, conservation values are hypothesized to have a negative significant effect on 'allow' (Hypothesis 3) and 'no conditions' (Hypothesis 4). These relations are expected to hold in all countries, i.e. regardless of the cultural context. We do not expect any differences in the effect sizes across the different countries (Hypothesis 5).

To address the question of how the value dimensions self-transcendence and conservation influence attitudes toward immigration in different countries, 
Table 4 Unstandardized effects (SE in parentheses) of value dimensions on Allow and No Conditions

Allow

Self-transcendence
Conservation

\begin{tabular}{|c|c|c|c|c|c|c|c|}
\hline GB & $0.744^{*}(-0.062)$ & $\mathrm{CZ}$ & $-0.603^{*}(-0.073)$ & $\mathrm{BE}$ & $1.494^{*}(-0.211)$ & $\mathrm{BE}$ & $-1.454^{*}(-0.121)$ \\
\hline FI & $0.732 *(-0.052)$ & PL & $-0.587^{*}(-0.085)$ & SE & $1.473^{*}(-0.136)$ & SI & $-1.338^{*}(-0.167)$ \\
\hline $\mathrm{CZ}$ & $0.730^{*}(-0.094)$ & GB & $-0.558^{*}(-0.042)$ & FR & $1.222^{*}(-0.161)$ & FR & $-1.301^{*}(-0.106)$ \\
\hline PL & $0.727^{*}(-0.112)$ & FR & $-0.547^{*}(-0.039)$ & IE & $1.074^{*}(-0.160)$ & SE & $-1.291^{*}(-0.102)$ \\
\hline $\mathrm{BE}$ & $0.676^{*}(-0.078)$ & $\mathrm{BE}$ & $-0.509^{*}(-0.044)$ & FI & $0.988^{*}(-0.133)$ & IE & $-1.190^{*}(-0.119)$ \\
\hline GR & $0.622^{*}(-0.089)$ & SI & $-0.508^{*}(-0.062)$ & $\mathrm{NO}$ & $0.965^{*}(-0.149)$ & NL & $-1.166^{*}(-0.091)$ \\
\hline $\mathrm{CH}$ & $0.599^{*}(-0.050)$ & GR & $-0.504^{*}(-0.070)$ & GB & $0.943^{*}(-0.140)$ & $\mathrm{NO}$ & $-1.118^{*}(-0.096)$ \\
\hline FR & $0.586^{*}(-0.059)$ & FI & $-0.481^{*}(-0.034)$ & NL & $0.894 *(-0.136)$ & GB & $-1.022^{*}(-0.095)$ \\
\hline NO & $0.585^{*}(-0.055)$ & $\mathrm{HU}$ & $-0.458^{*}(-0.107)$ & DK & $0.886^{*}(-0.154)$ & ES & $-0.949^{*}(-0.099)$ \\
\hline SI & $0.567^{*}(-0.093)$ & $\mathrm{NO}$ & $-0.445^{*}(-0.035)$ & SI & $0.885^{*}(-0.247)$ & AT & $-0.911^{*}(-0.059)$ \\
\hline $\mathrm{HU}$ & $0.557^{*}(-0.135)$ & ES & $-0.424^{*}(-0.043)$ & $\mathrm{CH}$ & $0.859^{*}(-0.154)$ & FI & $-0.909^{*}(-0.087)$ \\
\hline IE & $0.548^{*}(-0.059)$ & IE & $-0.418^{*}(-0.044)$ & AT & $0.709^{*}(-0.082)$ & DK & $-0.811^{*}(-0.095)$ \\
\hline ES & $0.541^{*}(-0.053)$ & PT & $-0.415^{*}(-0.076)$ & $\mathrm{HU}$ & $0.644^{*}(-0.311)$ & $\mathrm{HU}$ & $-0.792^{*}(-0.247)$ \\
\hline AT & $0.537^{*}(-0.029)$ & NL & $-0.411^{*}(-0.032)$ & $\mathrm{DE}$ & $0.587^{*}(-0.099)$ & $\mathrm{DE}$ & $-0.774^{*}(-0.063)$ \\
\hline $\mathrm{DE}$ & $0.535^{*}(-0.039)$ & $\mathrm{DE}$ & $-0.410^{*}(-0.024)$ & ES & $0.501^{*}(-0.120)$ & $\mathrm{CH}$ & $-0.719^{*}(-0.081)$ \\
\hline NL & $0.511^{*}(-0.049)$ & $\mathrm{CH}$ & $-0.397^{*}(-0.026)$ & $\mathrm{CZ}$ & $0.411(-0.228)$ & $\mathrm{CZ}$ & $-0.570^{*}(-0.177)$ \\
\hline PT & $0.485^{*}(-0.095)$ & AT & $-0.349^{*}(-0.020)$ & PT & $0.198(-0.185)$ & PT & $-0.413^{*}(-0.149)$ \\
\hline DK & $0.484^{*}(-0.049)$ & $\mathrm{DK}$ & $-0.342^{*}(-0.030)$ & PL & $-0.028(-0.279)$ & PL & $-0.299(-0.211)$ \\
\hline SE & $0.467^{*}(-0.037)$ & SE & $-0.296^{*}(-0.027)$ & GR & $-0.541^{*}(-0.174)$ & GR & $0.012(-0.138)$ \\
\hline
\end{tabular}

No Conditions

\section{Self-transcendence Conservation}

${ }^{*} \mathrm{P}<0.05$.

we estimated their direct impact on the variables 'allow' and 'no conditions' simultaneously in the 19 countries. Table 4 provides the unstandardized regression coefficients.

Self-transcendence and conservation exhibit significant effects on the variable 'allow'. Self-transcendence has a positive significant effect and conservation a negative significant effect on the variable 'allow' in all countries analysed. In other words, people who score high on self-transcendence values are also more willing to allow larger numbers of immigrants into the country. In contrast, those scoring high on conservation values are more negative toward immigration. Differences in the strength of this effect across countries seem to be present. We will address the issue of effect size differences in the next section.

Next, we turn to the effects of self-transcendence and conservation values on the variable 'no conditions'. Self-transcendence exhibits a positive effect on the variable 'no conditions' in 15 countries. In these countries, people with high scores on self-transcendence values are more prone to reject imposing conditions on immigration. In contrast, conservation displays a negative significant effect in 17 countries. In these countries, as expected, the tendency to reject conditions on immigration is lower among people who attribute high importance to conservation values.
Sixty-nine of the estimated 76 regression coefficients perform according to our hypotheses. Thus, the empirical results support our theoretical expectations on the relationship between these value orientations and attitudes toward immigration in most countries. They suggest that values explain attitudes toward immigration in most nations in a meaningful and similar way.

\section{Comparison of the Effects Across Nations}

The finding that partial metric invariance is present allows cross-country comparisons of the effect sizes of values on attitudes toward migration. It enables us to answer questions such as: Which countries have the strongest effects? Which countries have the weakest effects? And even more interesting, which countries have equal effects? Trying to form clusters of countries with equal effect sizes can be a cumbersome task. Given that our model contains 19 countries, an almost infinite number of partitions is possible. Inspired by Welkenhuysen-Gybels and van de Vijver (2001), we adopted a bottom-up strategy to form groups of countries with equal effect sizes. Following this strategy, firstly, the effects of the two countries with the highest agreement in effect size are constrained to be equal. A chi-square difference test is implemented 
Table 5 Clusters of countries by effect type and effect size (unstandardized) (SE in parentheses)

\begin{tabular}{|c|c|c|c|c|c|c|c|c|}
\hline \multirow{3}{*}{$\begin{array}{l}\text { Dependent } \\
\text { variable } \\
\text { Predictor/ } \\
\text { Cluster } \\
\text { number }\end{array}$} & \multicolumn{4}{|c|}{ Allow } & \multicolumn{4}{|c|}{ No conditions } \\
\hline & \multicolumn{2}{|c|}{ Self-transcendence } & \multicolumn{2}{|c|}{ Conservation } & \multicolumn{2}{|c|}{ Self-transcendence } & \multicolumn{2}{|c|}{ Conservation } \\
\hline & Countries & $\begin{array}{c}\text { Effect } \\
\text { (SE) }\end{array}$ & Countries & $\begin{array}{c}\text { Effect } \\
\text { (SE) }\end{array}$ & Countries & $\begin{array}{c}\text { Effect } \\
\text { (SE) }\end{array}$ & Countries & $\begin{array}{c}\text { Effect } \\
\text { (SE) }\end{array}$ \\
\hline 1 & $\begin{array}{l}\text { AT, CH, } \\
\text { DE, DK, } \\
\text { ES, FR, } \\
\text { HU, IE, } \\
\text { NL, NO, } \\
\text { PT, SE, SL }\end{array}$ & $\begin{array}{l}0.532^{*} \\
(-0.013)\end{array}$ & $\begin{array}{l}\text { AT, CH, } \\
\text { DE, DK, } \\
\text { ES, IE, NL, } \\
\text { NO, PT }\end{array}$ & $\begin{array}{l}-0.395^{*} \\
(-0.010)\end{array}$ & $\begin{array}{l}\text { BE, FR, IE, } \\
\text { SE }\end{array}$ & $\begin{array}{l}1.214^{*} \\
(-0.065)\end{array}$ & $\mathrm{BE}, \mathrm{FR}, \mathrm{SL}$ & $\begin{array}{l}-1.317^{*} \\
(-0.054)\end{array}$ \\
\hline 2 & $\begin{array}{l}\mathrm{BE}, \mathrm{CZ}, \mathrm{FI}, \\
\mathrm{GB}, \mathrm{GR}, \\
\mathrm{PL}\end{array}$ & $\begin{array}{l}0.668^{*} \\
(-0.023)\end{array}$ & $\begin{array}{l}\text { BE, FR, } \\
\text { GB, GR, } \\
\text { SL }\end{array}$ & $\begin{array}{l}-0.518^{*} \\
(-0.016)\end{array}$ & $\begin{array}{l}\mathrm{AT}, \mathrm{CH}, \\
\mathrm{DK}, \mathrm{FI}, \\
\mathrm{GB}, \mathrm{NL}, \\
\mathrm{NO}, \mathrm{SL}\end{array}$ & $\begin{array}{l}0.851^{*} \\
(-0.043)\end{array}$ & $\begin{array}{l}\text { AT, DK, } \\
\text { ES, FI, GB, } \\
\text { HU }\end{array}$ & $\begin{array}{l}-0.929^{*} \\
(-0.035)\end{array}$ \\
\hline 3 & & & $\mathrm{CZ}, \mathrm{PL}$ & $\begin{array}{l}-0.556^{*} \\
(-0.028)\end{array}$ & $\mathrm{DE}$ & $\begin{array}{l}0.567^{*} \\
(-0.088)\end{array}$ & $\begin{array}{l}\text { IE, NL, } \\
N O, S E\end{array}$ & $\begin{array}{l}-1.159^{*} \\
(-0.043)\end{array}$ \\
\hline 4 & & & FI, HU & $\begin{array}{l}-0.451^{*} \\
(-0.019)\end{array}$ & ES & $\begin{array}{l}0.523^{*} \\
(-0.085)\end{array}$ & $\mathrm{CH}, \mathrm{DE}$ & $\begin{array}{l}-0.745^{*} \\
(-0.045)\end{array}$ \\
\hline 5 & & & SE & $\begin{array}{l}-0.313^{*} \\
(-0.023)\end{array}$ & GR & $\begin{array}{l}-0.510^{*} \\
(-0.174)\end{array}$ & $\mathrm{CZ}$ & $\begin{array}{l}-0.519^{*} \\
(-0.170)\end{array}$ \\
\hline 6 & & & & & $\mathrm{CZ}$ & $\begin{array}{l}0.361 \\
(-0.220)\end{array}$ & GR & $\begin{array}{l}0.017 \\
(-0.136)\end{array}$ \\
\hline 7 & & & & & PL & $\begin{array}{l}-0.108 \\
(-0.265)\end{array}$ & $\mathrm{PT}$ & $\begin{array}{l}-0.388^{*} \\
(-0.145)\end{array}$ \\
\hline 8 & & & & & $\mathrm{PT}$ & $\begin{array}{l}0.191 \\
(-0.184)\end{array}$ & PL & $\begin{array}{l}-0.249 \\
(-0.202)\end{array}$ \\
\hline 9 & & & & & $\mathrm{HU}$ & $\begin{array}{l}0.800^{*} \\
(-0.085)\end{array}$ & & \\
\hline
\end{tabular}

${ }^{*} \mathrm{P}<0.05$.

to test whether the model fit deteriorates significantly. If this turns out to be the case, the equality constraint is removed and the conclusion is drawn that all countries have different effects. If the model fit does not become worse, an equality constraint is added for the country that is most similar to the formed cluster. Again, a chi-square difference test is used to determine whether this constraint in tenable. This process continues until there is no country whose effect agrees with the effects of the two nations whose effects were constrained to be equal. The countries that are not part of the cluster are scrutinized again by means of the same bottom-up process. This method was repeated for each of the four effects of values on attitudes toward immigration. The unstandardized coefficients resulting from the bottom-up approach are shown in Table 5.

For the effect of self-transcendence on 'allow', only two clusters of countries are found. The first cluster contains the majority of the countries (13 out of 19).
The hypothesis that the effect of self-transcendence on 'allow' is equal across these countries cannot be rejected. The common effect is 0.532 , and this value is significant. For the second cluster, the effect is significantly stronger (0.668). Despite the statistical difference, self-transcendence has a similar effect on 'allow' in both clusters. For the effect of conservation on 'allow' we find five clusters of countries. Again, the differences in the effect size between the clusters are relatively small. The strongest effect is found for the third cluster, containing only the Czech Republic and Poland $(-0.556)$. Sweden, on the other hand, is an outlier and has the weakest effect $(-0.313)$. The other countries are situated somewhere in between.

With respect to the effect of self-transcendence on 'no conditions', the strongest effects are found for Belgium, France, Ireland, and Sweden (cluster 1; 1.214). Somewhat less strong was the effect in the second cluster, which-with the exception of Sloveniaincludes only Western or Northern European countries. 
From this point on, none of the countries had equal effects according to the chi-square difference test. Hungary, Germany, and Spain had a positive effect, the Czech Republic, Poland, and Portugal no effect, and Greece was an outlier with a negative effect. Finally, for the effect of conservation on the variable 'no conditions' we found eight relatively small clusters. The strongest similar negative effect $(-1.317)$ was found in the first cluster, which included France, Belgium, and Slovenia. Countries in the second cluster had also a negative effect, but it was somewhat weaker $(-0.929)$. The effect size of the countries in the third cluster is situated in between the effect sizes of the first two clusters $(-1.159)$. Two German-speaking countries (Switzerland and Germany) constituted the fourth cluster. From this point on, none of the other countries had equal effects according to the chi-square difference test, with Greece and Poland having an effect not significantly different from zero.

This type of analysis allows us to estimate the potential explanatory power that values have on attitudes toward immigration in the different countries. Despite our finding that almost all countryspecific effects have the same sign, significantly different effect sizes are found across the countries. This is especially the case for the effects of selftranscendence and conservation on 'no conditions'. Providing a sound explanation for the differences in effect size is less evident, since marked patterns are not always present. Probably, a combination of factors in the national context is responsible for the diverging effect size. In the final section, we offer explanations for some country-specific differences.

\section{The Robustness of the Findings in the Presence of Control Variables}

In the previous section, we found that-despite some differences with respect to the strength of the effectsvalues have a substantial impact on attitudes toward immigration. In the literature however, various other variables were quite successfully used to explain attitudes toward out-groups in general. Education, for example, was repeatedly found to have a positive effect (Jackman and Muha, 1984; Coenders and Scheepers, 2003; Kunovich, 2004). Other variables that were shown to have an effect include age, economic situation, political orientation, and religiosity (see for example Billiet, 1995; Fetzer, 2000; Semyonov et al., 2006). As some of these characteristics might also be related to the scores on the human value scales (Schwartz, 2006), there is a possibility that the relation between values and attitudes is spurious.
In order to test whether the value-approach really offers additional explanatory power over existing models, we estimated the effect of values on attitudes toward immigration under control for the following individual variables: age, gender, level of education, household income, religiosity, attendance of religious services, and left-right orientation. Additionally, we controlled for four contextual variables, namely GDP per capita, GDP growth, the inflow of immigrants, and the stock of foreign-born population. Controlling for these variables in a multi-level analysis did not change the substantive results (Appendix 1$)^{6}$ and the values conservation and self-transcendence remained the strongest predictors for attitudes toward immigration. Their effect did not exclude other explanatory variables proposed in the literature. Values may complement rather than exclude other variables in explaining attitudes toward immigration. ${ }^{7}$

\section{Explaining Effect Size Differences Across Nations}

Notwithstanding the finding that values have an impact on attitudes toward immigration in the vast majority of countries, we also detected some cross-country variation in the sizes of the effects. Giving a sound explanation for these observed differences in effect sizes is a very difficult task especially given the relatively small differences between countries. Probably, the differences in effect sizes are the result of complex processes, in which certain individual characteristics of the population, historical path dependence, and national characteristics interact. The fact that various of these factors are extremely hard to measure, and that information on 19 countries only does not allow us to take too many elements into consideration at once, makes it very hard to model the cross-country variation in effect sizes in detail. In spite of these difficulties, we undertake an attempt to link the observed differences in effect size to two national context variables, namely GDP per capita and the gross immigration inflow (per 1,000 inhabitants). ${ }^{8}$ We do this by examining correlation coefficients between the effect sizes and these national characteristics. Self-evidently, this part of the research has an exploratory character. Table 6 provides a summary of the correlations between effect sizes and the two national context variables.

First and foremost, the GDP per capita seems to affect the strength of the value effects. The effects of self-transcendence and conservation on 'allow' appear to be more pronounced in countries with a low GDP per capita. In other words: human values give a stronger prediction of the willingness to allow 
Table 6 Correlations between effect sizes and national context variables

$$
\begin{array}{cc}
\text { GDP per } & \text { Inflow of } \\
\text { capita } & \text { immigrants } \\
& \text { per } 1,000 \\
& \text { inhabitants }
\end{array}
$$

\begin{tabular}{|c|c|c|}
\hline $\begin{array}{l}\text { Self-transcendence } \\
\text { on allow }(+)\end{array}$ & -0.28 & -0.45 \\
\hline Conservation on allow $(-)$ & 0.58 & 0.53 \\
\hline $\begin{array}{l}\text { Self-transcendence on } \\
\text { 'no conditions' }(+)\end{array}$ & 0.61 & -0.06 \\
\hline $\begin{array}{l}\text { Conservation on 'no } \\
\text { conditions' }(-)\end{array}$ & -0.46 & 0.09 \\
\hline
\end{tabular}

immigrants for poorer countries than for richer ones. For the effects on 'no conditions', the opposite pattern is found: human values tend to provide a stronger explanation in richer countries. The relation between effect sizes and GDP per capita is quite strong, as three out of four correlation coefficients exceed the absolute value of 0.45 . It may be the case that in poorer countries, the immigration debate is focused on the quantity of immigration, as inhabitants of these countries may fear that immigration will constitute a competition with their already limited economic resources. Values may be related to such fears (universalistic individuals may fear less than conservative individuals) and as a consequence be better predictors for 'allow' in poorer countries. The question whether migration should be conditioned on certain criteria on the other hand, may occupy a more central role in the debate in wealthier countries. If polarization on this topic took place along value divides, this could have resulted in stronger effects of values on 'no conditions' in richer countries. Further research is needed to verify these explanations.

Second, the inflow of immigrants is connected to the effect sizes for only one of the concepts, namely 'allow'. It is not surprising that the inflow of immigrants is related to the effects on 'allow', as this concept is explicitly linked to the willingness of the respondent to allow immigrants into the country. 'No conditions' on the other hand, deals with modalities for granting entrance in the first place. In countries with a high level of immigration, human values tend to affect 'allow' only to a lesser extent. This may be due to the fact that inhabitants of these immigration countries have a larger amount of information-obtained via personal experiences or through the mass media-at their disposal in the attitude formation process. Therefore, these persons might fall back on general human values only to a lesser extent than inhabitants without this information. Nevertheless, we should not forget that even in countries with high levels of immigration, human values play an important role in the formation of attitudes toward immigration.

\section{Summary and Conclusions}

This article examines the effect of two value dimensions taken from the basic values theory of Schwartz, namely, self-transcendence and conservation, on attitudes toward immigration. The effects are compared across 19 countries in a multiple-group setting using data from the first wave of the ESS. We addressed three research questions:

1. Whether self-transcendence values have a positive effect on support for immigration.

2. Whether conservation values have a negative effect on support for immigration.

3. Whether these effects are cross-nationally invariant.

In cross-cultural survey research, more methodological issues are often involved than in a single country survey research (van de Vijver and Leung, 1997; Welkenhuysen-Gybels and van de Vijver, 2001). Initially, the test of measurement invariance addressed the question of whether the latent variables in the model have the same metric across the countries in the study. This is a necessary condition for drawing conclusions about differences and similarities in the effect of the value dimensions on the dependent variables, attitudes toward immigration. After concluding that the constructs were measured in a (partially) equivalent way, we continued on with the comparative analysis.

The multiple-group SEM model supported our hypotheses. In 15 of the 19 countries we compared, all effects worked in the hypothesized direction. Our fifth hypothesis suggesting invariance of the effects of values on attitudes toward immigration across countries was not supported by the data, as effects varied across the 19 countries. However, in spite of differences in effect sizes, these differences were rather small and value dimensions provided a sound explanation for attitudes toward immigration. Indeed, this mechanism seems to be quite universal in the countries studied. Furthermore, controlling for variables often used in the literature to explain anti-minority sentiments ${ }^{9}$ did not produce any change in our substantive results. 
We also investigated differences and similarities in these effects across nations by grouping the countries into clusters in which their effect sizes are not statistically different. We applied a bottom-up chi-square difference test approach. According to the cluster solutions, the effects on the variable 'allow' proved to be more homogenous than the effects on the variable 'no conditions'. Economic conditions (reflected in GDP per capita) and the inflow of immigrants appeared to be related to the strength of the coefficients between values and attitudes, suggesting possible interaction effects between these contextual variables and values. ${ }^{10}$

So far, the value concept has not reached the position it possibly deserves in the social sciences. One likely reason for this gap in the literature is that value research has suffered for a long time from the absence of an agreed-upon scale to measure values (Hitlin and Piliavin, 2004). However, the theoretical relevance of values to explain attitudes is very large. Human values can be seen as general principles that underpin attitudes toward more specific objects, such as immigration, and we have proposed the underlying mechanism for it which was tested empirically: human values whose motivational goals are promoted or blocked by the arrival of immigrants will affect attitudes toward immigration ${ }^{11}$ (for a general discussion on the importance of testing causal relations empirically with large-scale data see, e.g., Blossfeld, 1996; Goldthorpe, 1996). Furthermore, it is in line with Icek Ajzen's (2005) postulation that values may have an effect on attitudes. This is not part of the theory of planned behaviour, but 'can complement it... and thereby deepen our understanding of a behavior's determinants' (Ajzen, 2005: 134). ${ }^{12}$

For the first time, utilizing the data from the ESS, researchers are provided with an opportunity to apply an agreed-upon comparable measurement of values based on Schwartz' theory of basic human values to explain attitudes, opinions, and behaviour in different domains. This measurement has been validated in 20 countries using the ESS data, and displays construct validity (Davidov et al., in press). Researchers can now test whether patterns of value/ attitude and value/behaviour relations generalize across countries. Our study provides solid support for the effect of certain values on attitudes toward immigration in Europe, cross-nationally, and serves as an example of how such a cross-country comparison can be conducted.

\section{Acknowledgements}

The first and the fourth authors would like to thank the German Israeli Foundation (GIF), Project No. I-769-241.4. The first author would like to thank the Katholieke Universiteit Leuven for the post-doc fellowship, which supported part of the work on this article. The second author is grateful to the Fund for Scientific Research-Flanders (FWO-Vlaanderen) for the aspirant mandate, which made it possible to contribute to this article. We would like to thank Shalom Schwartz, Hermann Dülmer, and two anonymous reviewers for very helpful comments on an earlier version of this article. Special thanks to Lisa Trierweiler for the English proof of the manuscript.

\section{Notes}

1. Austria and Greece are not taken into account because immigration statistics for some years are lacking in the OECD database.

2. The study is about the effects of values on two dimensions or aspects of attitudes toward immigration and not attitudes toward immigrants or ethnic pre-judice. However, attitudes toward immigration are closely linked to ethnic prejudice and out-group attitudes. For further studies on attitudes toward out-groups in general and pre-judice see for example Adorno et al., 1950; Allport, 1954; Smith, 1981; Bierly, 1985; Schuetz and Six, 1996; Altemeyer, 1998; Bobo, 1999; Brewer, 1999; Whitley, 1999.

3. Originally, 22 countries participated in ESS round 1. However, Italy and Luxemburg are excluded because the value scales were omitted from the questionnaire in these two countries. Israel is excluded due to large differences in model structure that were revealed during the analysis. We chose all the European countries available in the first round of this survey in order to examine to what extent Europe is homogenous in the effect of values on attitudes towards immigration.

4. One could reasonably argue that the items measure opinions rather than attitudes, since they are rather specific. We rather treat them as attitudes, since they do not relate to a specific situation in a specific context. We consider opinions to be even more time and place specific than these items. We chose 
the best items based on confirmatory factor analyses.

5. We used the Full Information Maximum Likelihood (FIML) estimator to deal with the problem of missing values (Arbuckle, 2005).

6. Results of multi-level analyses with this type of data set should be interpreted carefully. First, multilevel modelling assumes random sampling at all levels. Here, random sampling at the country level is not present, as the countries were not selected by means of some sort of probability mechanism. Furthermore, simulation studies have shown that a group sample size of 19 countries only would lead to inaccurate estimation (Meuleman, 2007). However, the multi-level analysis is applied in our article as an additional support for the results of the multiple group analysis, which provides similar findings when these individual variables are accounted for and the country is held constant.

7. Another indication for the robustness of the effects of values is provided by Vala et al. (2007) with the ESS data, where values retained their significant effects on opposition to anti-racist policies in Europe after accounting for some country-level and several individual variables.

8. GDP per capita is operationalized as the GDP per capita of 2003 in thousands of dollars as reported by the OECD. The inflow of immigrants per capita is the gross immigration figure of 2001 (source: OECD, 2006) divided by the population figure in thousands.

9. See, for example, Coenders and Scheepers, 1998, 2003; Hagendoorn and Nekuee, 1999; Scheepers et al., 2002; Raijman et al., 2003; Dustmann and Preston, 2004; Gijsberts et al., 2004; Kunovich, 2004; Raijman and Semyonov, 2004; Raijman et al., 2006; Semyonov et al., 2006.

10. Another possible explanation for effect size differences across countries may be the different immigration laws. However, it is difficult, if not impossible to find or develop reliable measurements for the immigration laws and apply them for such a large number of countries.

11. A direct test of the underlying mechanism would imply the direct measurement of utility, which is very difficult (Green and Shapiro, 1994).
12. Although in this study we did not take behaviour into account, attitudes are considered an important determinant of behaviour in the theory of planned behaviour (Ajzen, 2005).

\section{References}

Allport, G. W. (1954). The Nature of Prejudice. Cambridge, MA: Perseus Books.

Adorno, T. W., Frenkel-Brunswick, E., Levinson, D. K. and Sanford, R. N. (1950). The Authoritarian Personality. New York: Harper.

Ajzen, I. (1993). Attitude theory and the attitudebehavior relation. In Krebs, D. and Schmidt, P. (Eds), New Directions in Attitude Measurement. Berlin: de Gruyter, pp. 41-57.

Ajzen, I. (2005). Attitudes, Personality and Behavior. New York: Open University Press.

Altemeyer, B. (1998). The other 'authoritarian personality'. Advances in Experimental Social Psychology, 30, 47-92.

Anderson, C. J. (1996). Economics, politics, and foreigners: populist party support in Denmark and Norway. Electoral Studies, 15, 497-511.

Arbuckle, J. L. (2005). Amos 6.0 User's Guide. Chicago: SPSS.

Ball-Rokeach, S. J. and Loges, W. E. (1994). Choosing equality: the correspondence between attitudes about race and the value of equality. Journal of Social Issues, 50, 9-18.

Bierly, M. M. (1985). Prejudice toward contemporary outgroups as a generalized attitude. Journal of Applied Social Psychology, 15, 189-199.

Billiet, J. B. (1995). Church involvement, individualism, and ethnic prejudice among Flemish Roman Catholics: new evidence of a moderating effect. Journal for the Scientific Study of Religion, 34, 224-233.

Billiet, J., Eisinga, R. and Scheepers, P. (1996). Ethnocentrism in the low countries: a comparative perspective. New Community, 22, 401-416.

Blalock, H. M. (1967). Toward a Theory of Minoritygroup Relations. New York: John Wiley \& Sons.

Blossfeld, H.-P. (1996). Macro-sociology, rational choice theory, and time: a theoretical perspective on the empirical analysis of social processes. European Sociological Review, 12, 181-206.

Bobo, L. (1999). Prejudice as group position: microfoundations of a sociological approach to racism and race relations. Journal of Social Issues, 55, 445-472. 
Brewer, M. B. (1999). The psychology of prejudice: ingroup love and outgroup hate? Journal of Social Issues, 55, 429-444.

Byrne, B. M., Shavelson, R. J. and Muthén, B. (1989). Testing for the equivalence of factor covariance and mean structures: the issue of partial measurement invariance. Psychological Bulletin, 105, 456-466.

Cheung, G. W. and Rensvold, R. B. (2002). Evaluating goodness-of-fit indexes for testing measurement invariance. Structural Equation Modeling, 9, 233-255.

Coenders, M. and Scheepers, P. (1998). Support for ethnic discrimination in the Netherlands 1979-1993, effects of period, cohort, and individual differences. European Sociological Review, 14, 405-422.

Coenders, M. and Scheepers, P. (2003). The effect of education on nationalism and ethnic exclusionism: an international comparison. Political Psychology, 24, 313-343.

Davidov, E., Schmidt, P. and Schwartz, S. (2008). Bringing values back in: the adequacy of the European social survey to measure values in 20 countries. Public Opinion Quarterly. In press.

Duriez, B., Luyten, P., Snauwaert, B. and Hutsebaut, D. (2002). The importance of religiosity and values in predicting political attitudes: evidence for the continuing importance of religiosity in Flanders (Belgium). Mental Health, Religion of Culture, 5, 35-54.

Dustmann, C. and Preston, I. (2004). Racial and Economic Factors in Attitudes to Immigration. London: CreAM.

Eagly, A. H. and Chaiken, S. (1993). The Psychology of Attitudes. Fort Worth, TX: Harcourt Brace Jovanovich.

Esses, V. M., Haddock, G. and Zanna, M. P. (1993). Values, stereotypes, and emotions as determinants of intergroup attitudes. In Mackie, D. M. and Hamilton, D. S. (Eds), Affect, Cognition and Stereotyping: Iintergroup Processes in Group Perception. San Diego: Academic Press.

Fetzer, J. S. (2000). Economic self-interest or cultural marginality? Anti-immigration sentiment and nativist political movements in France, Germany and the USA. Journal of Ethnic and Migration Studies, 26, 5-23.

Fishbein, M. and Ajzen, I. (1975). Belief, Attitude, Intention and Behavior: An Introduction to Theory and Research. Reading, MA: Addison-Wesley.

Gijsberts, M., Hagendoorn, L. and Scheepers, P. (Eds), (2004). Nationalism and Exclusion of Migrants.
Cross-national Comparisons. Aldershot, Hants, England: Ashgate.

Goldthorpe, J. H. (1996). The quantitative analysis of large-scale data-sets and rational action theory: for a sociological alliance. European Sociological Review, 12, 109-126.

Green, D. P. and Shapiro, I. (1994). Pathologies of Rational Choice Theory. A Critique of Applications in Political Science. New Haven: Yale University Press.

Hagendoorn, L. and Nekuee, S. (Eds), (1999). Education and Racism. A Cross-national Inventory of Positive Effects of Education on Ethnic Tolerance. Aldershot, Hants, England: Ashgate.

Harkness, J. A., van de Vijver, F. J. R. and Mohler, P. Ph. (Eds.), (2003). Cross-cultural Survey Methods. New York: John Wiley.

Hitlin, S. and Piliavin, J. A. (2004). Values: reviving a dormant concept. Annual Review of Sociology, 30, 359-393.

Horn, J. L. and McArdle, J. (1992). A practical and theoretical guide to measurement invariance in aging research. Experimental Aging Research, 18, 117-144.

Hui, C. H. and Triandis, H. C. (1985). Measurement in cross-cultural psychology: a review and comparison of strategies. Journal of Cross-Cultural Psychology, 16, 131-152.

Iser, J. and Schmidt, P. (2005). Werte und Big Five: Trennbarkeit der Konzepte und Erklärungskraft für politische Orientierungen [Values and the Big Five: Separation of the Concepts and Explanatory Power for Political Orientations]. In Schuhmann, S. (Ed.), Persönlichkeit. Eine vergessene Größe der empirischen Sozialforschung. Wiesbaden: Verlag für Sozialwissenschaften, pp. 301-320.

Jackman, M. R. and Muha, M. J. (1984). Education and intergroup attitudes: moral enlightenment, superficial democratic commitment, or ideological refinement? American Sociological Review, 49, 751-769.

Jöreskog, K. G. (1971). Simultaneous factor analysis in several populations. Psychometrika, 36, 409-426.

Kaplan, D. (1989). Model modification in covariance structure analysis: application of the expected parameter change statistic. Multivariate Behavioral Research, 24, 285-305.

Katz, I. and Hass, R. G. (1988). Racial ambivalence and American value conflict: correlational and priming studies of dual cognitive structures. Journal of Personality and Social Psychology, 55, 893-905.

Kunovich, R. M. (2004). Social structural position and prejudice: an exploration of cross-national 
differences in regression slopes. Social Science Research, 33, 20-44.

LeVine, R. A. and Campbell, D. T. (1972). Ethnocentrism: Theories of Group Conflict, Ethnic Attitudes, and Group Behavior. New York: John Wiley \& Sons.

Lubbers, M. (2001). Exclusionistic electorates. Extreme right-wing voting in Western Europe. Unpublished doctoral dissertation, Interuniversity Center for Social Science Theory and Methodology, Nijmegen, The Netherlands.

Meloen, J. D., Van der Linden, G. and De Witte, H. (1996). A test of the approaches of Adorno et al., Lederer and Altemeyer of authoritarianism in Belgian laders: a research note. Political Psychology, 17, 643-656.

Meuleman, B. (2007). The small-N problem in crossnational survey research: accuracy assessment of multi-level SEM by means of a Monte Carlo study. Paper presented at the 2nd EASR Conference, Prague, Czech Republic, 25-29th June.

Meuleman, B. and Billiet, J. (2005). Attitudes toward migration in Europe: a cross-cultural and contextual approach. Paper presented at the 1st EASR Conference, Barcelona, Spain, 18-22nd July.

OECD.(2006). International Migration Outlook 2006. Paris: OECD.

Olzak, S. and Nagel, J. (1986). Competitive Ethnic Relations. New York: Academic Press.

Pantoja, A. (2006). Against the tide? core American values and attitudes toward US immigration policy in the mid-1990s. Journal of Ethnic and Migration Studies, 32, 515-531.

Peterson, R. S. (1994). The role of values in predicting fairness judgments and support of affirmative action. Journal of Social Issues, 50, 95-115.

Raijman, R., Davidov, E., Schmidt, P. and Hochman, O. (2006). What does a nation owe non-citizens? National attachments, perception of threat and attitudes toward granting citizenship rights in comparative perspective. Paper presented at the RC-28 Conference of the ISA, Nijmegen, The Netherlands, 11-14th May.

Raijman, R. and Semyonov, M. (2004). Perceived threat and exclusionary attitudes towards foreign workers in Israel. Ethnic and Racial Studies, 27, 780-799.

Raijman, R., Semyonov, M. and Schmidt, P. (2003). Do foreigners deserve rights? Determinants of public views towards foreigners in Germany and Israel. European Sociological Review, 19, 379-392.
Roberts, A. H. and Rokeach, M. (1956). Anomie, authoritarianism, and prejudice: a replication. The American Journal of Sociology, 61, 355-358.

Rock, D. A., Werts, C. E. and Flaugher, R. L. (1978). The use of analysis of covariance structures for comparing the psychometric properties of multiple variables across populations. Multivariate Behavioral Research, 13, 403-418.

Rokeach, M. (1968). The role of values in public opinion research. Public Opinion Quarterly, 32, 547-559.

Rokeach, M. (1973). The Nature of Human Values. New York: The Free Press.

Sagiv, L. and Schwartz, S. H. (1995). Value priorities and readiness for out-group social contact. Journal of Personality and Social Psychology, 69, 437-448.

Saris, W. E., Satorra, A. and Sörbom, D. (1987). The detection and correction of specification errors in structural equation models. In Clogg, C. C. (Ed.), Sociological Methodology. San Francisco: JosseyBass, pp. 105-129.

Scheepers, P., Gijsberts, M. and Coenders, M. (2002). Ethnic exclusion in European countries. Public opposition to civil rights for legal migrants as a response to perceived ethnic threat. European Sociological Review, 18, 17-34.

Schuetz, H. and Six, B. (1996). How strong is the relationship between prejudice and discrimination? A meta-analytic answer. International Journal of Intercultural Relations, 20, 441-462.

Schwartz, S. H. (1992). Universals in the content and structure of values: theoretical advances and empirical tests in 20 countries. In Zanna, P. (Ed.), Advances in Experimental Social Psychology. Volume 25, San Diego: Academic Press, pp. 1-65.

Schwartz, S. H. (1994). Are there universal aspects in the structure and contents of human values? Journal of Social Issues, 50, 19-45.

Schwartz, S. H. (2006). A theory of cultural value orientations: explication and applications. Comparative Sociology, 5, 132-187.

Schwartz, S. H., Melech, G., Lehmann, A. and Burgess, S. et al. (2001). Extending the crosscultural validity of the theory of basic human values with a different method of measurement. Journal of Cross-Cultural Psychology, 32, 519-542.

Semyonov, M., Raijman, R. and Gorodzeisky, A. (2006). The rise of anti-foreigner sentiment in European societies, 1988-2000. American Sociological Review, 71, 426-449.

Sherif, M. and Sherif, C. W. (1969). Social Psychology. New York: Harper \& Row. 
Sides, J. and Citrin, J. (2007). European opinion about immigration: the role of identities, interests and information. British Journal of Political Science, 37, 477-504.

Smith, A. W. (1981). Racial tolerance as a function of group position. American Sociological Review, 46, 558-573.

Sniderman, P. M., Hagendoorn, L. and Prior, M. (2004). Predisposing factors and situational triggers: exclusionary reactions to immigrant minorities. American Political Science Review, 98, 35-49.

Snijders, T. A. B. and Bosker, R. J. (1994). Multilevel Analysis: An Introduction to Basic and Advanced Multilevel Modeling. London: Sage.

Steenkamp, J.-B. E. M. and Baumgartner, H. (1998). Assessing measurement invariance in cross national consumer research. Journal of consumer research, 25, 78-90.

Sumner, W. G. (1960). Folkways: A Study of the Sociological Importance of Usages, Manners, Customs, Mores and Morals. New York: New American Library.

Vala, J., Ramos, A. and Pereira, C. (2007). Prejudice, threat perception and opposition to anti-racist policies in Europe. Paper presented at the 2nd ESRA conferences, Prague, 25-29 June 2007.

van de Vijver, F. J. R. and Leung, K. (1997). Methods and Data Analysis for Cross-cultural Research. Thousand Oaks: Sage.

Vandenberg, R. J. and Lance, C. E (2000). A review and synthesis of the measurement invariance literature: suggestions, practices and recommendations for organizational research. Organizational Research Methods, 3, 4-69.
Welkenhuysen-Gybels, J. G. J. and van de Vijver, F. J. R. (2001). A comparison of methods for the evaluation of construct equivalence in a multigroup setting. Paper presented at the Annual Meeting of the American Statistical Association, 5-9 August 2001.

Whitley, Jr B. E. (1999). Right-wing authoritarianism, social dominance orientation, and prejudice. Journal of Personality and Social Psychology, 77, 126-134.

\section{Authors' Addresses}

Eldad Davidov (to whom correspondence should be addressed), GESIS-ZA, University of Cologne, Liliencronstr. 6, 50931 Cologne, Germany, or Faculty of Social Sciences, University of Mannheim, A5, 6, 68131 Mannheim, Germany. Tel: +49-621-1812049; Fax: +49-621-1812048; Email:_Davidov@za.uni-koeln.de or Davidov@sowi.uni-mannheim.de

Bart Meuleman, Centre for Sociological Research (CeSO), Catholic University of Leuven, Belgium.

Jaak Billiet, Centre for Sociological Research (CeSO), Catholic University of Leuven, Belgium.

Peter Schmidt, Faculty of Social and Cultural Sciences, Institute for Political Sciences, Justus-LiebigUniversität Giessen, Germany.

Manuscript received: April 2007 


\section{Appendix}

Table A1 Multilevel models for Allow and No Conditions

\begin{tabular}{|c|c|c|c|c|c|c|c|c|c|c|c|c|}
\hline \multirow[b]{2}{*}{$\begin{array}{l}\text { Fixed effects } \\
\text { Intercept } \\
\text { Conservation }\end{array}$} & \multicolumn{4}{|c|}{$\begin{array}{c}\text { Allow } \\
\text { Model } 2\end{array}$} & \multicolumn{2}{|c|}{ Model 3} & \multicolumn{2}{|c|}{ Model 1} & \multicolumn{2}{|c|}{$\begin{array}{c}\text { No Conditions } \\
\text { Model } 2\end{array}$} & \multicolumn{2}{|c|}{ Model 3} \\
\hline & 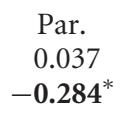 & $\begin{array}{r}(T \text {-value }) \\
(0.50) \\
(-\mathbf{2 0 . 9 5 )}\end{array}$ & $\begin{array}{c}\text { Par. } \\
0.029 \\
-\mathbf{0 . 1 9 8}^{*}\end{array}$ & $\begin{array}{r}(T \text {-value }) \\
(0.43) \\
(-\mathbf{1 4 . 5 0})\end{array}$ & $\begin{array}{c}\text { Par. } \\
0.050 \\
-\mathbf{0 . 1 9 8}^{*}\end{array}$ & $\begin{array}{r}(T \text {-value }) \\
(0.67) \\
(-\mathbf{1 4 . 3 7 )}\end{array}$ & $\begin{array}{c}\text { Par. } \\
0.020 \\
-\mathbf{0 . 2 5 3}^{*}\end{array}$ & $\begin{array}{r}(T \text {-value }) \\
(0.38) \\
(-\mathbf{1 0 . 8 4})\end{array}$ & $\begin{array}{c}\text { Par. } \\
0.023 \\
-\mathbf{0 . 1 7 4}^{*}\end{array}$ & $\begin{array}{r}(T \text {-value }) \\
(0.41) \\
(-7.64)\end{array}$ & $\begin{array}{c}\text { Par. } \\
0.020 \\
-\mathbf{0 . 1 7 3}^{*}\end{array}$ & $\begin{array}{r}(T \text {-value }) \\
(0.34) \\
(-7.60)\end{array}$ \\
\hline $\begin{array}{l}\text { Self-transcendence } \\
\text { Gender } \\
\text { Age } \\
\text { Education } \\
\text { Income } \\
\text { Religiosity } \\
\text { Religious services } \\
\text { Left-right }\end{array}$ & $0.232^{*}$ & (15.85) & $\begin{array}{r}0.191^{*} \\
-0.102^{*} \\
-0.020^{*} \\
0.171^{*} \\
0.062^{*} \\
0.025^{*} \\
0.035^{*} \\
-0.084^{*}\end{array}$ & $\begin{array}{r}(11.91) \\
(-15.34) \\
(-3.32) \\
(25.56) \\
(7.99) \\
(3.30) \\
(4.33) \\
(-13.77)\end{array}$ & $\begin{array}{r}\mathbf{0 . 1 9 1} \\
-0.102^{*} \\
-0.020^{*} \\
0.171^{*} \\
0.063^{*} \\
0.026^{*} \\
0.034^{*} \\
-0.084^{*}\end{array}$ & $\begin{array}{r}(11.84) \\
(-15.32) \\
(-3.32) \\
(25.55) \\
(7.98) \\
(3.31) \\
(4.27) \\
(-13.77)\end{array}$ & $0.108^{*}$ & $(6.34)$ & $\begin{array}{r}\mathbf{0 . 0 7 1} \\
-0.153^{*} \\
0.027^{*} \\
0.079^{*} \\
-0.007 \\
-0.001 \\
0.032^{*} \\
-0.113^{*}\end{array}$ & $\begin{array}{r}(3.91) \\
(-21.58) \\
(4.34) \\
(11.08) \\
(-0.87) \\
(-0.16) \\
(3.75) \\
(-17.27)\end{array}$ & $\begin{array}{r}\mathbf{0 . 0 7 1} \\
-0.153^{*} \\
0.027^{*} \\
0.079^{*} \\
-0.007 \\
-0.002 \\
0.032^{*} \\
-0.113^{*}\end{array}$ & $\begin{array}{r}(3.91) \\
(-21.56) \\
(4.34) \\
(11.09) \\
(-0.89) \\
(-0.18) \\
(3.73) \\
(-17.27)\end{array}$ \\
\hline $\begin{array}{l}\text { Macro variables } \\
\text { GDP per capita } \\
\text { GDP growth } \\
\text { Foreign born } \\
\text { Immigration inflow }\end{array}$ & & & & & $\begin{array}{r}-0.115 \\
0.119 \\
0.153 \\
-0.032\end{array}$ & $\begin{array}{r}(-1.28) \\
(1.61) \\
(1.58) \\
(-0.42)\end{array}$ & & & & & $\begin{array}{r}0.008 \\
0.002 \\
0.002 \\
-0.055\end{array}$ & $\begin{array}{r}(0.13) \\
(0.05) \\
(0.03) \\
(-1.02)\end{array}$ \\
\hline $\begin{array}{l}\text { Random effects } \\
\text { Random intercept } \\
\text { Slope conservation } \\
\text { Slope self-trans. } \\
\text { Residual variance }\end{array}$ & $\begin{array}{l}\text { Par. } \\
0.095^{*} \\
0.002^{*} \\
0.003^{*} \\
0.769^{*}\end{array}$ & $\begin{array}{r}(Z \text {-value }) \\
(2.81) \\
(1.84) \\
(2.06) \\
(104.14)\end{array}$ & $\begin{array}{l}\text { Par. } \\
0.079^{*} \\
0.002^{*} \\
0.004^{*} \\
0.719^{*}\end{array}$ & $\begin{array}{r}(Z \text {-value }) \\
(2.80) \\
(1.89) \\
(2.22) \\
(104.12)\end{array}$ & $\begin{array}{l}\text { Par. } \\
0.090 \\
0.002 \\
0.004 \\
0.719\end{array}$ & $\begin{array}{r}(Z \text {-value }) \\
(2.33) \\
(1.91) \\
(2.23) \\
(104.12)\end{array}$ & $\begin{array}{l}\text { Par. } \\
0.049^{*} \\
0.008^{*} \\
0.004^{*} \\
0.880^{*}\end{array}$ & $\begin{array}{r}(Z \text {-value }) \\
(2.79) \\
(2.44) \\
(2.20) \\
(105.60)\end{array}$ & $\begin{array}{l}\text { Par. } \\
0.053^{*} \\
0.008^{*} \\
0.005^{*} \\
0.843^{*}\end{array}$ & $\begin{array}{r}(Z \text {-value }) \\
(2.78) \\
(2.43) \\
(2.28) \\
(105.58)\end{array}$ & $\begin{array}{l}\text { Par. } \\
0.058^{*} \\
0.008^{*} \\
0.005^{*} \\
0.843^{*}\end{array}$ & $\begin{array}{r}(Z \text {-value }) \\
(1.98) \\
(2.43) \\
(2.28) \\
(105.58)\end{array}$ \\
\hline
\end{tabular}

*P $<0.05$

Par. indicates parameter.

Values of primary interest have been printed in bold.

All variables were standardized prior to analysis, so that coefficients are approximately standardized parameters (Snijders \& Bosker, 1994). By consequence, it is allowed to compare effect sizes within the model. In the multiple-group comparison, on the other hand, unstandardized coefficients are reported since they allow a comparison of effects across countries. The analysis was conducted on the same data set as in the multiple-group comparison. The sample size used for the first three models was 21,741, and for the last three models 22,357. Greece and Slovenia were excluded because of missing values at the contextual level for the variables immigration inflow (Greece) and foreign born (Slovenia). The rate of foreign born could be computed based on the ESS data for Slovenia, but this would still be a proxy and we preferred to avoid it. The income variable had a large rate of missing values causing a large loss of cases. However, there is evidence that income is not missing at random, and imputation would have produced biased estimates. We preferred not to omit this variable from the analysis, since it is a central variable used in the literature to explain attitudes toward immigrants.

Operationalization of the variables: Age is measured in years. Gender is a dichotomous variable receiving the value of 1 for males and 2 for females. Education level is coded as an ordinal variable, ranging from 0 to 6: 0, Not completed primary education; 1, Primary or first stage of basic; 2, Lower secondary or second stage of basic; 3 , Upper secondary; 4, Post secondary, non-tertiary; 5 , First stage of tertiary; 6, Second stage of tertiary. Attendance of religious services ranged from 1 (never) to 7 (every day). Religiosity ranged from 0 , not at all religious to 10 , very religious. Left-right orientation was coded as 0, left to 10, right. Household income was subdivided in 12 classes (1-12). GDP per capita, GDP per capita of 2003 in thousands of dollars as reported by the OECD. GDP growth, GDP per capita annual growth rate 1990-1999; Immigration inflow, gross immigration figure in thousands, 2001; Foreign born, stock of foreign born population as a percentage of the total population, 2001. 